\title{
Attenuation of intestinal inflammation in IL- 10 deficient mice by a plasmid carrying Lactococcus lactis strain
}

\author{
Meritxell Zurita-Turk ${ }^{1 *}$ (D), Bianca Mendes Souza ${ }^{1}$, Camila Prósperi de Castro ${ }^{1}$, Vanessa Bastos Pereira', \\ Vanessa Pecini da Cunha', Tatiane Melo Preisser ${ }^{1}$, Ana Maria Caetano de Faria², \\ Denise Carmona Cara Machado ${ }^{3}$ and Anderson Miyoshi ${ }^{1}$
}

\begin{abstract}
Background: Inflammatory bowel diseases (IBD) are intestinal disorders characterized by inflammation in the gastrointestinal tract (GIT) and to date, no efficient treatments exist. Interleukin-10 (IL-10), one of the most important anti-inflammatory cytokines of the immune response, has been under study due to its potential for IBD therapy; however, systemic treatments lead to undesirable side effects and oral administration is limited due to its quick degradation. To avoid these bottlenecks, we previously engineered an invasive Lactococcus lactis (L. lactis) strain capable of delivering, directly to host cells, a eukaryotic DNA expression vector coding for IL-10 of Mus musculus (pValac:I-10) that diminished inflammation in two induced mouse models of intestinal inflammation. Thus, the aim of this study was to analyze its therapeutic effect in the IL-10-deficient mouse model $\left(\mathrm{IL}-10^{-/-}\right)$that spontaneously and gradually develops an inflammation that modifies the immune system and resembles Crohn's disease (CD) in humans, and evaluate if it would also diminish and/or prevent the onset of this disease.

Results: Oral administration of L. lactis MG1363 FnBPA+ (pValac:il-10) to IL-10 ${ }^{-1-}$ mice not only led to IL-10 production by these, but consequently also diminished the severe development of the disease, with animals showing lower macroscopic scores and histological damages, increased IL-10 levels and tendency to lower pro-inflammatory cytokine levels.

Conclusions: The results of this study, together with the previously published ones using this DNA deliverybased strategy, show that it is capable of creating and maintaining an anti-inflammatory environment in the GIT and thus effectively diminish the onset of inflammation in various mouse models.
\end{abstract}

Keywords: Inflammatory bowel diseases, Interleukin-10, Lactococcus lactis, pValac:il-10, IL-10-deficient mice

\footnotetext{
* Correspondence: meritxellzt@gmail.com

'Laboratório de Tecnologia Genética, Departamento de Biologia Geral, Instituto de Ciências Biológicas, Universidade Federal de Minas Gerai, Av. Antônio Carlos, 6627, Pampulha, 31, Belo Horizonte, MG 270-901, Brazil

Full list of author information is available at the end of the article
}

C C The Author(s). 2020 Open Access This article is licensed under a Creative Commons Attribution 4.0 International License, which permits use, sharing, adaptation, distribution and reproduction in any medium or format, as long as you give appropriate credit to the original author(s) and the source, provide a link to the Creative Commons licence, and indicate if changes were made. The images or other third party material in this article are included in the article's Creative Commons licence, unless indicated otherwise in a credit line to the material. If material is not included in the article's Creative Commons licence and your intended use is not permitted by statutory regulation or exceeds the permitted use, you will need to obtain permission directly from the copyright holder. To view a copy of this licence, visit http://creativecommons.org/licenses/by/4.0/ The Creative Commons Public Domain Dedication waiver (http://creativecommons.org/publicdomain/zero/1.0/) applies to the data made available in this article, unless otherwise stated in a credit line to the data. 


\section{Background}

Inflammatory bowel diseases (IBD), including Crohn's disease (CD) and ulcerative colitis (UC), are intestinal disorders characterized by chronic inflammation in the gastrointestinal tract (GIT), and although sharing clinical and pathological features, they differ in their histological aspect and cytokine profiles [1]. The exact etiology and pathogenesis of these diseases are unclear despite much research in the last decades, but it is nowadays generally accepted that they are caused by deregulation of the mucosal immune system towards the native intestinal microbiota in genetically susceptible individuals, resulting in an inappropriate and excessive activation of the intestinal immune system [2]. As no unique and defined causal agent is responsible for the development of these diseases, current treatment proposals, including antiinflammatory drugs, immunosuppressants and antibiotics, only improve the patient's quality of life while presenting serious side effects and no cure, revealing that better, cheaper and longer lasting treatments are necessary [3].

IL-10-deficient mice (IL-10 ${ }^{-/-}$) not raised in a defined specific-pathogen-free (SPF) environment develop a spontaneous gut inflammation, called enterocolitis, that is characterized by weight loss and anemia at the age of 4-6 weeks, lethal up to the age of 3 months [4], and is most severe in the colon, involving the small intestine to a lesser extent. The typical inflammatory lesions of this disease are discontinuous and transmural, and include epithelial hyperplasia, crypt abscesses, ulcers, mucin depletion and bowel wall thickening with infiltration of lymphocytes, plasma cells, macrophages, eosinophils and neutrophils [4]; its development is mediated by CD4+ T cells and an uncontrolled Th1 response [5].

Interleukin-10 (IL-10) is one of the most important anti-inflammatory cytokines in shaping mucosal immune responses in the gut $[4,6]$. This cytokine is produced by regulatory $\mathrm{T}$ cells, epithelial cells, macrophages, dendritic cells and B1 cells [7] and therefore presents many important properties, including stimulation of B-cell differentiation and immunoglobulin secretion [8] and suppression of macrophage activation to inhibit inflammatory cytokines production. IL-10 is a good therapeutic candidate against IBD due to its immunosuppressive activity and central role in downregulating inflammatory cascades [9, 10]; systemic and oral treatments with recombinant human IL-10 were first tested in CD patients but presented important drawbacks, such as short half-life and extreme sensitivity of the gastrointestinal tract [11-14]. Steidler et al. developed an IL-10-producing Lactococcus lactis ( $L$. lactis) strain [15] and although initial studies showed promising results, no statistically significant difference in mucosal healing between patients receiving the recombinant strains and a placebo were observed [16].
To overcome IL-10's sensitivity and survival in the gastrointestinal tract, our research group used a novel strategy based on the use of the eukaryotic DNA expression vector pValac, constructed by ourselves in 2009, and a L. lactis strain to deliver and trigger DNA expression by epithelial cells of the host. Basically, after oral administration of the bacterial strain carrying the plasmid of interest, these enter target cells, bacteria suffer lysis and plasmids are liberated to the cytoplasm and transferred into the cell's nucleus. Subsequently, the cell's machinery is responsible for the expression of the ORF of interest, translation and protein synthesis [17]. Advantages of this strategy include the targeting of mucosal immunity, simple technology and low cost as well as safe use of L. lactis, as this strain does not colonize the gastrointestinal tract and transits it between 2 and 3 days, not becoming part of the normal gut flora.

The constructed L. lactis strain carrying the therapeutic pValac:il-10 plasmid delivers it directly to the host's cells. This strategy does not only ensure a more effective and direct delivery of the therapeutic plasmid but consequently a higher and more efficient IL-10 in situ production. This strategy successfully showed its anti-inflammatory effect and intestinal inflammation prevention in two induced inflammatory mouse models: TNBS (2,4,6-Trinitrobenzenesulfonic acid) and DSS (Dextran Sodium Sulphate) $[18,19]$, showing to be innovative and promising for the therapeutic IBD treatment.

In this line, the aim of the present work was to evaluate the L. lactis MG1363 FnBPA+ (pValac:il-10) strain as therapy in IL- $10^{-/-}$mice and evaluate its capacity to diminish and/or prevent the onset of enterocolitis.

\section{Results}

\section{Evaluation of the animals' weight}

The animals' weight was assessed throughout the 6 weeks of experimentation, starting at the age of 2 weeks. All experimental groups presented an initial similar weight gain, according to the normal growth of these animals and development of the disease (Fig. 1). However, IL- $10^{-/-}$mice from the $\mathrm{KO}$ and FnBPA groups showed an overall lower weight gain after 2 weeks of experimentation, when compared with the healthy control and the pValac:il-10 groups. On the other hand, $\mathrm{IL}-10^{-/-}$mice from the pValac:il-10 group showed rapid weight gain which equaled that of the healthy control group after the 6 weeks of experimentation. Moreover, this group also showed statistically significant differences with the $\mathrm{KO}$ and FnBPA groups in weeks 4,5 and $6(p<0.001)$.

\section{Macroscopic and histologic evaluation}

The healthy control group presented neither macroscopic nor histologic intestinal lesions (Figs. 2 and 3a) 


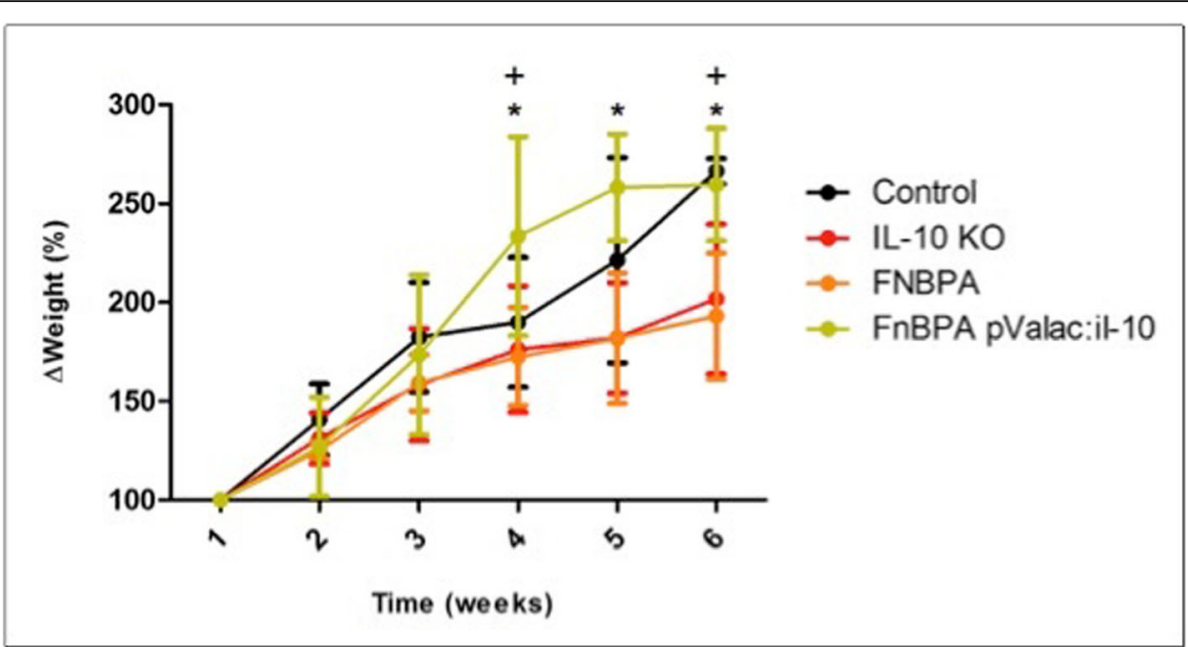

Fig. 1 Corporal weight variation (\%) of mice along the 6 weeks of experimentation. Healthy control group: negative control of intestinal inflammation, $\mathrm{KO}: \mathrm{IL}-10^{-1-}$ mice - positive control of intestinal inflammation; FnBPA: IL-10 ${ }^{-/-}$mice that received the L. lactis MG1363 FnBPA+ strain; pValac:il-10: IL-10-1- mice that received the L. lactis MG1363 (pValac:il-10) strain. +: Experimental group (control) whose percentage of corporal weight is statistically different from those of group pValac:il-10 in week 4 and groups KO and FnBPA in week 6 . *: Experimental group (pValac:il-10) whose corporal weight percentage is statistically different from those of groups KO and FnBPA in weeks 4,5 and 6 ( $p<0.001$ ). The data is presented as the mean \pm SD

and is not shown in Fig. 2 as its macroscopic score was 0 . Hematoxylin-eosin (HE) staining of samples of the ascending colon (AC) showed that this group presented a normal histological architecture with an intact mucosa, thin submucosal and serosal layers, muscular layer thickness compatible with the analyzed segment and normal proportion of goblet cells. No signs of degenerative, vascular, inflammatory or pathological cell proliferation processes were observed (Fig. 3a).

All IL-10 $0^{-/-}$mice, except those from the pValac:il-10 group, presented similar macroscopic and histologic damage scores regarding the samples of their AC (Figs. 2 and

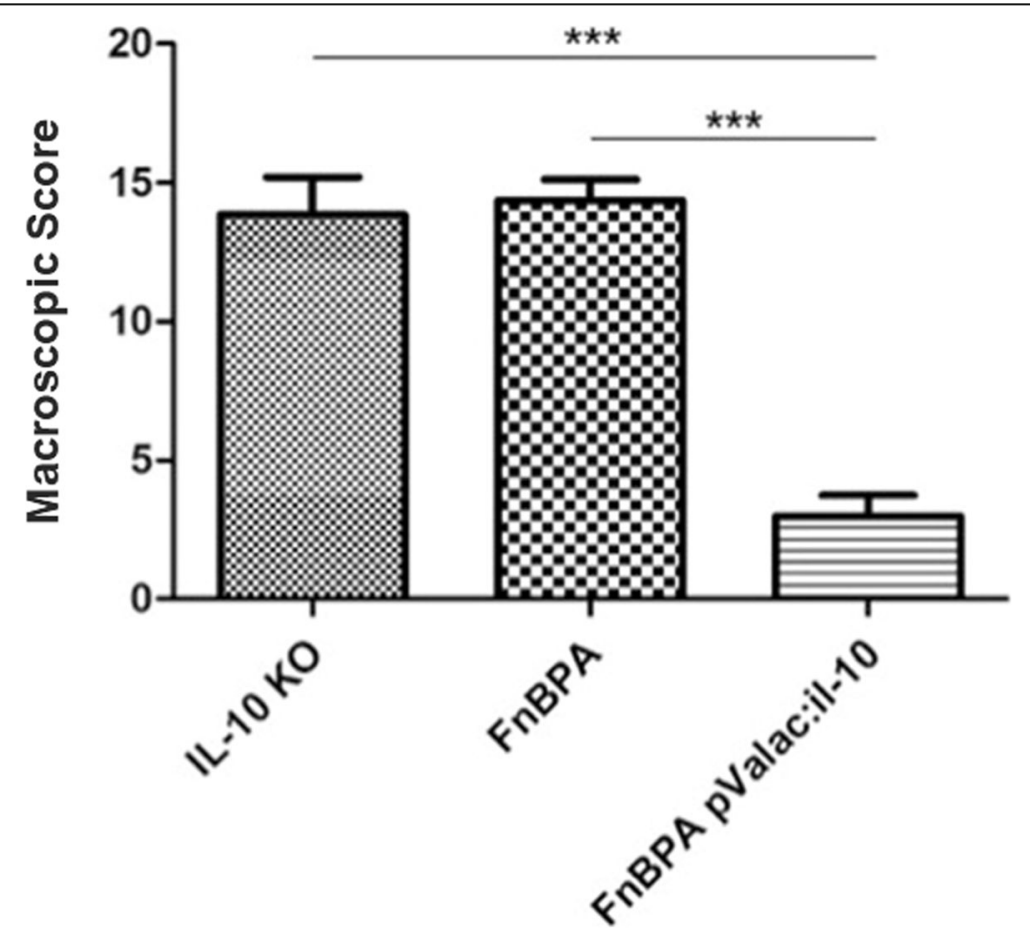

Fig. 2 Macroscopic score of the different groups. Bars represent the mean $N=9 \pm S D$. Asterisks represent statistical significance $(* * *<0.0001)$ 


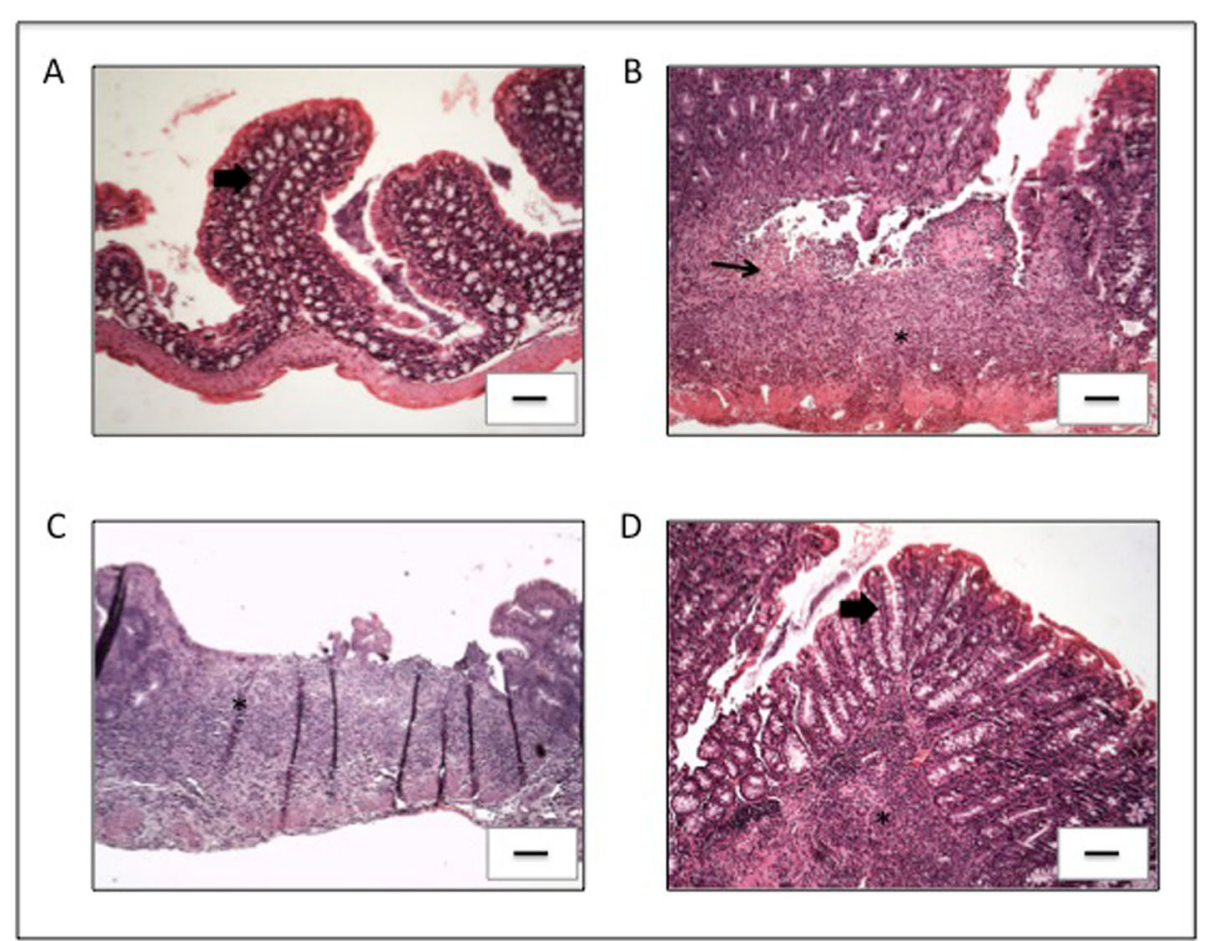

Fig. 3 Histopathology of changes in the AC of all experimental groups. a Control group; b KO group; c FnBPA group and $\mathbf{d}$ pVala:il-10 group. Presence of inflammatory infiltrate (asterisks) and mucosal lesion (black thin arrow) can be observed in varied degrees of intensity. The thick arrow highlights the preserved mucosal architecture with the presence of goblet cells. The strains were obtained from the tissue of AC stained with HE. The bar in each image represents $100 \mu \mathrm{m}$

3b-c). It was possible to observe a compromised histological architecture with moderate inflammatory infiltrate in the mucosa and presence of mononuclear cells. Areas of erosion and reduction of goblet cells were also observed, as well as moderate inflammatory infiltrate in the submucosal layer and oedema. No evident alterations were observed in the muscular and the serosa layer (Fig. 3b and c). These results show that the disease strongly affected the $\mathrm{AC}$ region.

The pValac:il-10 group, however, showed that administration of L. lactis MG1363 FnBPA+ (pValac:il-10) to $\mathrm{IL}-10^{-/-}$mice was capable of strongly attenuating the pathology's development, presenting a much lower macroscopic damage score and statistically significant differences with the KO and FnBPA groups (Fig. 2). Furthermore, the pValac:il-10 group also showed significant improvement of histological patterns: the mucosa of the $\mathrm{AC}$ of this group presented light inflammation in less than $40 \%$ of animals, with no inflammatory alteration in the rest, no present signals of erosion nor depletion of goblet cells and no inflammatory infiltrate in the submucosal layer (Fig. 3d).

After evaluation of the histopathological damage of AC samples, the histological score was performed, and as expected, the IL-10 ${ }^{-/-}$control and L. lactis MG1363 FnBPA+ groups showed statistically significant differences with the L. lactis MG1363 FnBPA+ (pValac:il-10) group (Fig. 4).

HE staining of samples of the descending colon (DC) of the healthy control group showed that all fragments of this group presented patterns of normality, with normal histological architecture and integral mucosa without erosion and with presence of goblet cells in the adequate proportion. The muscular layer thickness observed, thin submucosal and serosal layers, were compatible with the analyzed segment and no signs of degenerative or pathological cell proliferation processes were observed. Some few animals presented a light inflammatory infiltrate in the region of the mucosa and oedema in the submucosa (Fig. 5a).

IL-10 $0^{-/-}$animals of the $\mathrm{KO}$ and FnBPA groups presented a compromised histological architecture. HE staining of DC samples of these groups showed moderate inflammatory infiltrate in the mucosa, marked by mononuclear cells; however, no areas of erosion, ulceration or with goblet cells reduction were observed. Moderate oedema and light infiltrate were observed in the submucosa region, with no evident alteration in the muscular and serosa layers (Fig. 5b and c). These results show that the disease also strongly affects the descendant region of the colon. 


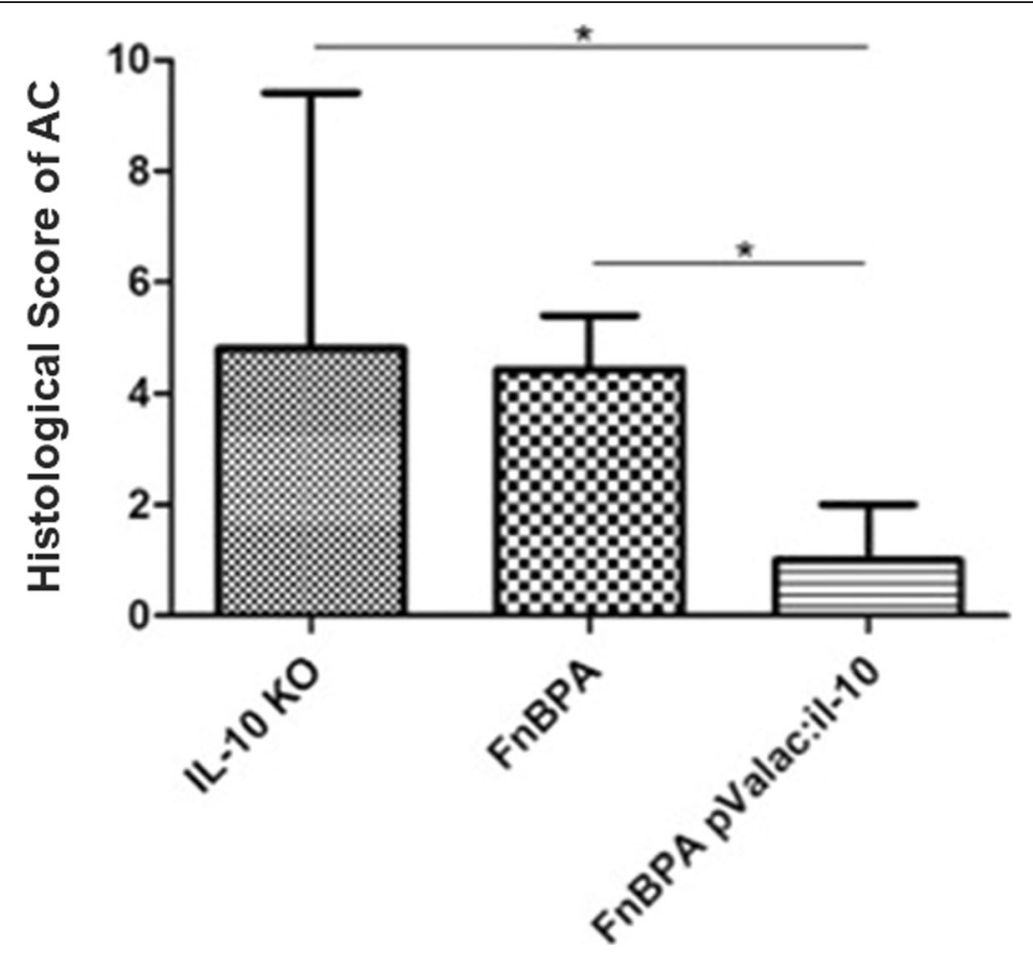

Fig. 4 Histological score of AC samples of all groups. Bars represent the mean $N=9 \pm S D$. Asterisks represent statistical significance $\left({ }^{*} p<0.05\right)$

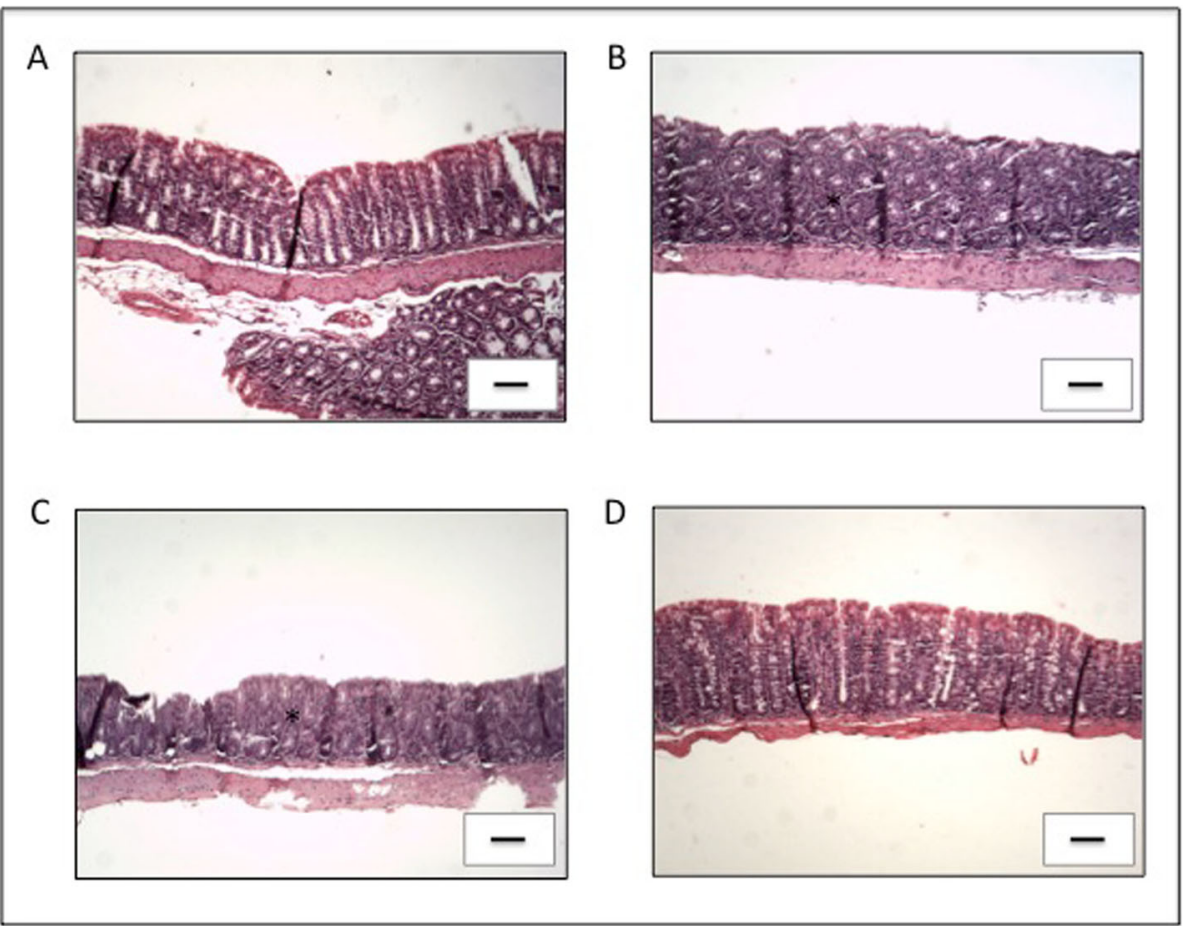

Fig. 5 Histopathology of changes in the DC of all experimental groups. a Control group; b KO group; c FnBPA group and d pVala:il-10 group. Presence of inflammatory infiltrate (asterisks) can be observed in varied degrees of intensity. The strains were obtained from the tissue of DC stained with HE. The bar in each image represents $100 \mu \mathrm{m}$ 
IL-10 ${ }^{-/-}$animals that received the L. lactis MG1363 FnBPA+ (pValac:il-10) strain showed an attenuated pathologic pattern, with light inflammatory infiltrate in the mucosa and no observed alteration in the epithelium. Moreover, alterations in the submucosa (oedema and infiltrate) were considered light or even absent in some animals (Fig. 5d).

Again, after analysis of histopathological damages of DC samples, the histological score of all groups was realized and showed, as expected, that the $\mathrm{KO}$ and FnBPA groups showed major histological damage scores than the L. lactis MG1363 FnBPA+ (pValac:il-10) group (Fig. 6).

Administration of L. lactis MG1363 FnBPA+ (pValac:il-10) results in IL-10 production in all evaluated tissues

All IL-10 $0^{-/-}$mice from the groups that did not receive any treatment (KO and FnBPA) did not produce IL-10 (Fig. 7). This in turn resulted in statistically significant differences $(p<0.0006)$ with the control group in the small intestine and spleen (Fig. 7c-d) and with the pValac:il-10 group in all evaluated tissues. As expected, $L$. lactis MG1363 FnBPA+ (pValac:il-10) administration to $\mathrm{IL}-10^{-/-}$mice led to $\mathrm{IL}-10$ production in all evaluated tissues. It was quite surprising to observe that IL-10 levels in the control group were lower than in the pValac:il-10 group, especially in the $\mathrm{AC}$ and spleen (Fig. 7a and $\mathrm{d}$ ), where these were even statistically significant $(p<0.05$ and $p<0.001$, respectively).

\section{Administration of the pValac:il-10 plasmid tends to alter the production of IL- 6 and IFN- $\gamma$ cytokines}

L. lactis MG1363 FnBPA+ (pValac:il-10) administration to IL-10 $0^{-/}$mice resulted in lower IL-6 production levels in the $\mathrm{AC}$ when compared to both the $\mathrm{KO}$ and FnBPA groups; however, these were not statistically significant (Fig. 8a). In the small intestine, although not being statistically significant, IL-6 levels of the pValac:il-10 were lower than in the $\mathrm{KO}$ group but slightly higher than in the FnBPA group (Fig. 8b).

In relation to IFN- $\gamma$ production, the pValac:il-10 group presented lower levels both in the AC and small intestine with no statistically significant difference with the other groups (Fig. 9). Again, regarding lower IL-6 levels in the pValac:il-10 group, administration of the L. lactis MG1363 FnBPA+ (pValac:il-10) strain to IL-10 ${ }^{-/-}$mice tended to reduce IFN- $\gamma$ production levels.

\section{No bacterial translocation was observed after oral administration}

No bacterial translocation was detected in the spleen and liver up to $24 \mathrm{~h}$ following oral administration of bacterial strains (Table 1).

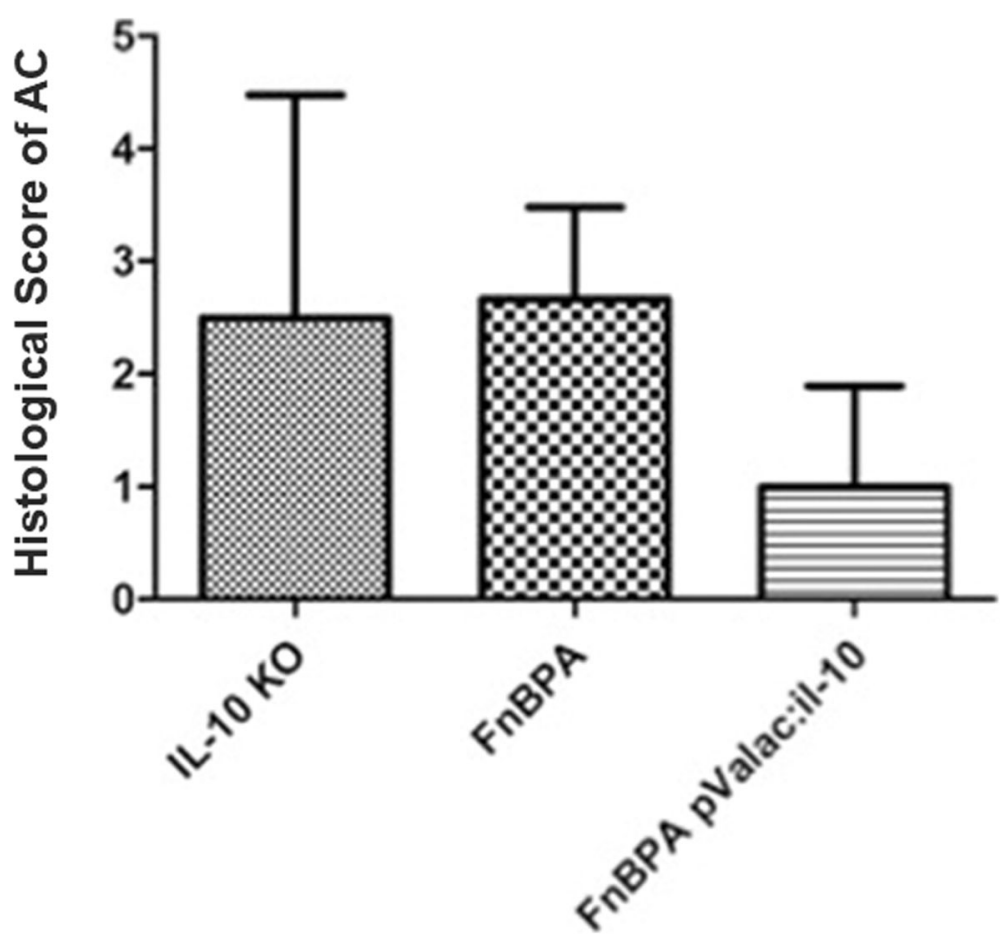

Fig. 6 Histological score of DC samples of all groups. Bars represent the mean $N=9 \pm$ SD 


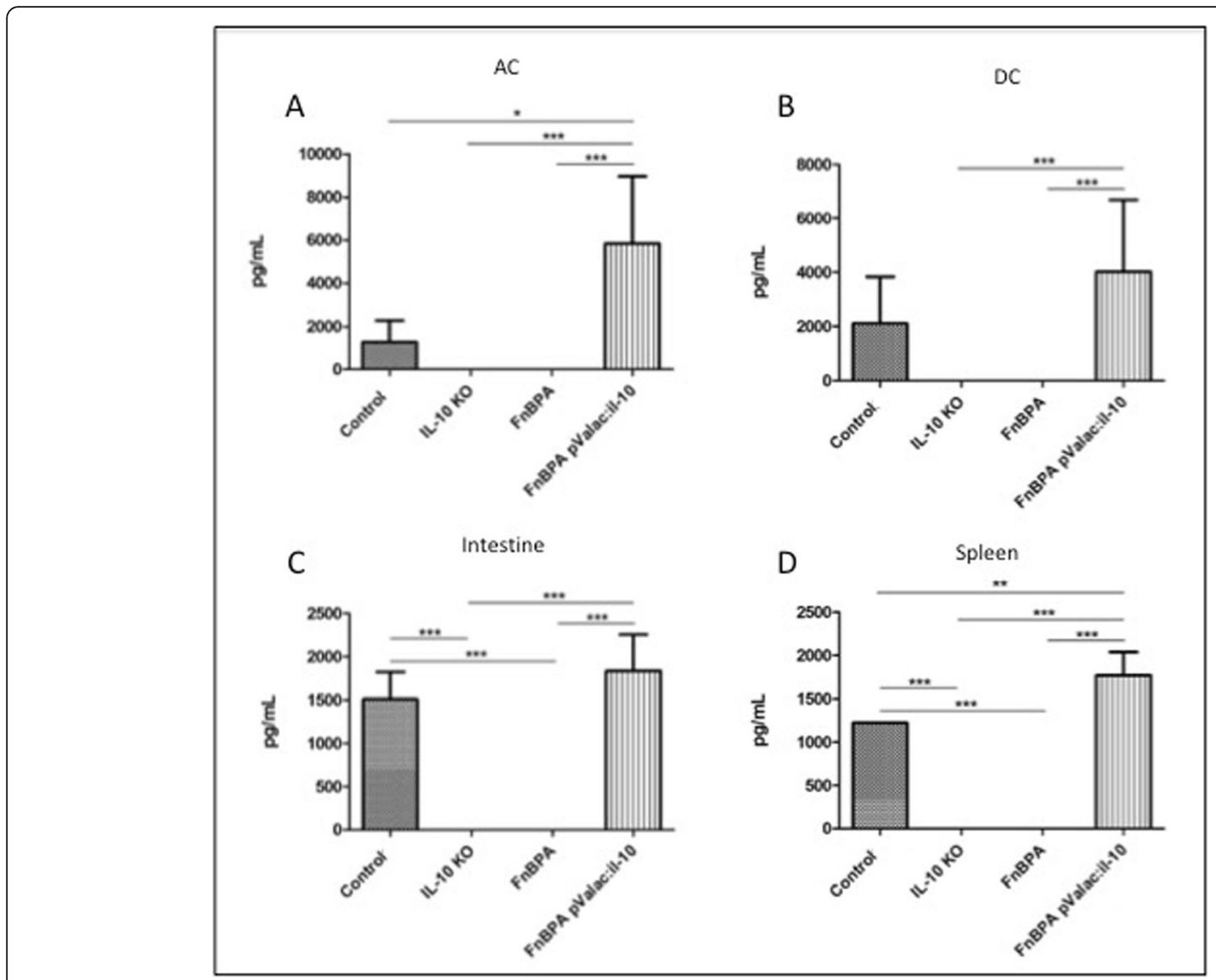

Fig. 7 Administration of the pValac:il-10 plasmid resulted in IL-10 production by IL-10-/- mice in all evaluated tissues. Levels of IL-10 in (a) AC, (b) DC, (c) small intestine and (d) spleen of control, KO, FnBPA and pValac:il-10 groups. Bars represent the mean $N=9 \pm$ SD. The asterisks represent statistical significance $\left({ }^{*} p<0.05,{ }^{* *} p<0.001\right.$ or $\left.{ }^{* *} p<0.0006\right)$

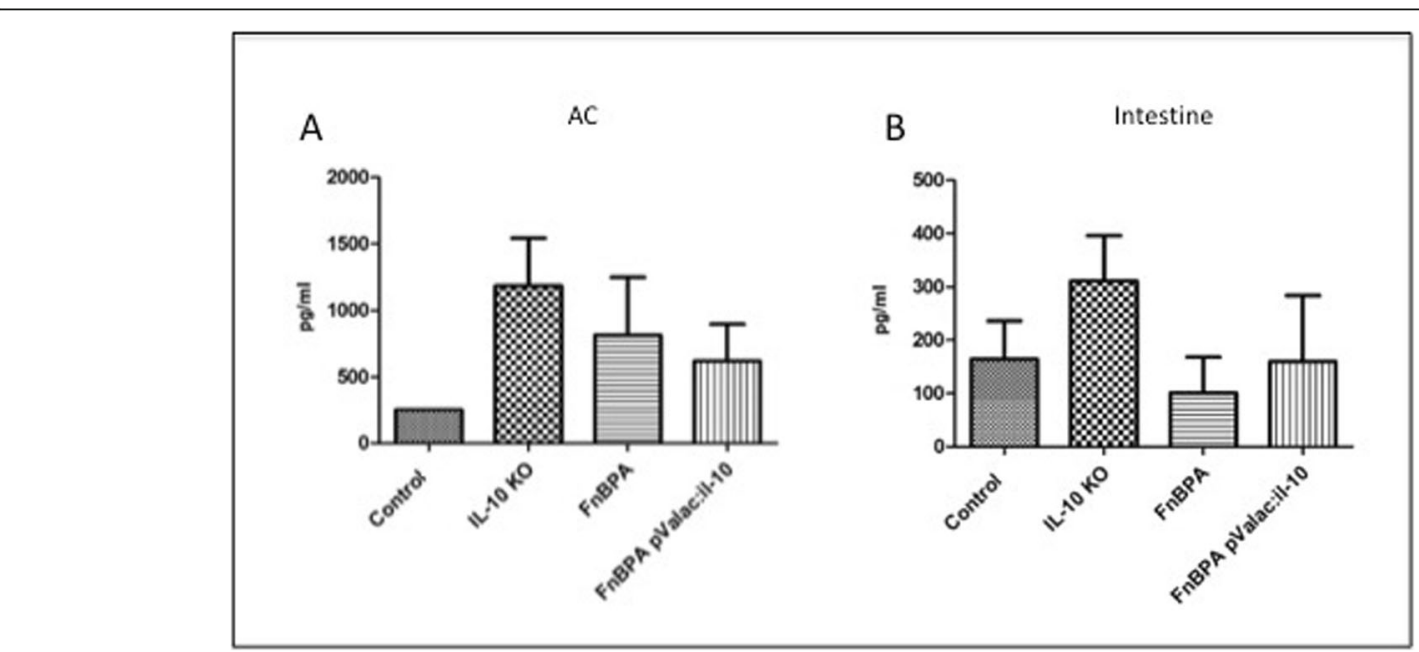

Fig. 8 Administration of the pValac:il-10 plasmid modulates the production of IL-6 in all tissues evaluated. Levels of IL-6 in (a) AC and (b) small intestine of control, KO, FnBPA and pValac:il-10 groups. Bars represent the mean $N=9 \pm S D$ 


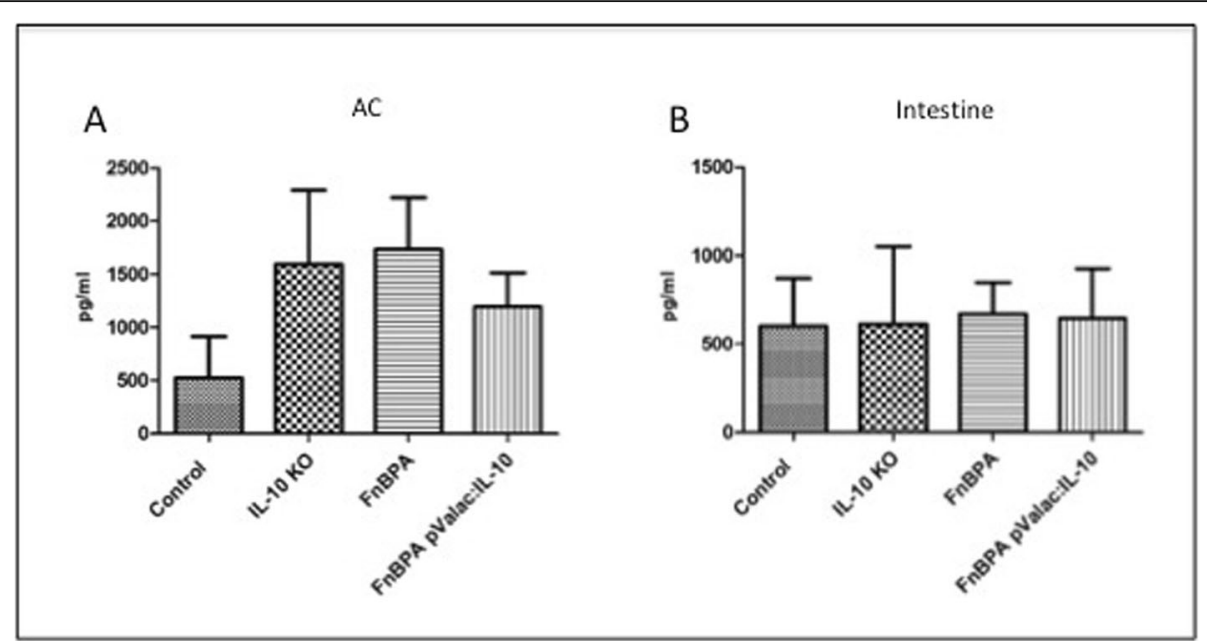

Fig. 9 Effect of the pValac:il-10 plasmid administration in IFN- $\gamma$ production. Levels of IFN- $\gamma$ in (a) AC and (b) small intestine of control, KO, FnBPA and pValac:il-10 groups. Bars represent the mean $N=9 \pm$ SD

\section{Discussion}

Much research in the last decades has focused in unveiling the etiology and pathogenesis of IBDs to develop therapies for their treatment, as no cure for them exists. Many strategies have based their research on the use of IL-10 due to its anti-inflammatory properties and key role in the development of the disease, as evidenced by IL-10 $0^{-/-}$mice, which develop enterocolitis, a severe disease in the colon characterized by weight loss, anemia and strong inflammatory lesions, apparent already at 4 weeks of age and lethal up to the age of 3 months, when maintained under conventional conditions [4].

The research and development of therapies using IL10 are based on its delivery directly at the intestinal mucosa, as its correct administration and targeting to the sites of inflammation has been the major bottleneck for successful results. These strategies have included the use of polymer-based microparticles [20] and the use of bacterial strains capable of secreting human IL-10 [21-23].

As a new and innovative approach for IL-10 production at inflammation sites, our research group developed a new strategy that involved the use of a L. lactis strain expressing FnBPA [17, 24], that has the capacity to efficiently internalize and trigger recombinant DNA expression by human epithelial cells, as delivery vehicle of a eukaryotic expression vector coding for IL-10, pValac:il-10, directly to the host's cells in the GIT for recombinant IL-10 in situ

Table 1 Bacterial translocation

\begin{tabular}{lcllll}
\hline & \multicolumn{7}{l}{ Time after gavage } \\
\cline { 2 - 6 } Bacterial Translocation & $2 \mathrm{~h}$ & $4 \mathrm{~h}$ & $6 \mathrm{~h}$ & $12 \mathrm{~h}$ & $24 \mathrm{~h}$ \\
\hline Liver & 0 & 0 & 0 & 0 & 0 \\
Spleen & 0 & 0 & 0 & 0 & 0 \\
\hline
\end{tabular}

production. This strategy does not only ensure a more effective and direct delivery of the therapeutic plasmid but consequently a higher and more efficient IL-10 production. This strategy showed to be capable of preventing inflammation in the TNBS-and DSSinduced mouse models $[18,19]$.

In this research, 2 weeks old mice received the pValac: il-10 plasmid during six consecutive weeks to evaluate its therapeutic effect. Macroscopic and histological analysis showed that non-treated mice presented an overall lower weight gain during this period while those under treatment showed a rapid weight gain equaling that of the healthy control group. This growth retardation in IL- $10^{-/-}$mice could be explained by the severe lesions in the GIT that led to disturbed nutrient absorption, contrary to the animals that received the therapy and consequently produced IL-10. Regarding the inflammatory damage in the $\mathrm{AC}$ and $\mathrm{DC}$, mice from the $\mathrm{KO}$ and FnBPA groups presented higher macroscopic damage scores and important lesions in the colon while IL-10 $10^{-1-}$ mice that received the pValac:il-10 plasmid showed an attenuated pathology's development and as such a much lower macroscopic damage scores, showing that IL-10 administration does prevent a worse onset of inflammation and therefore disease development.

Other important parameters measured during this period were the levels of pro-inflammatory and antiinflammatory cytokines. The normal gastrointestinal inflammatory response is tightly regulated, and the balance of pro-inflammatory and anti-inflammatory cytokines produced by CD $4+$ Th 1 and Th 2 cells is an important part of this regulatory process [25]. Intestinal inflammation in IL- $10^{-1-}$ mice is characterized by dysregulation of the immune system with regulatory $\mathrm{T}$ cells incapable of developing or functionally impaired in the absence of 
IL-10, leading to activation of Th1 cells and overproduction of pro-inflammatory cytokines resulting in chronic inflammation [5]. However, administration of the pValac:il-10 plasmid led to IL-10 production by mice naturally incapable of producing this cytokine, which, as a consequence, lowered the disease development when compared to $\mathrm{IL}-10^{-/-}$mice that did not receive any treatment. As already mentioned, IL-10 is essential to control intestinal immune responses. Moreover, some evidence suggests that IL-10 can inhibit the translocation of nuclear factor- $k B$, inhibiting the immediate-early pro-inflammatory response [26] and downregulate acute inflammatory responses.

This IL-10 production altered the production of proinflammatory cytokines, such as IL-6, which presented lower levels in all tissues of treated mice. IL- 6 is produced by $\mathrm{T}$ and $\mathrm{B}$ lymphocytes, which infiltrate inflammatory lesions in $\mathrm{IL}-10^{-/-}$mice, and which presents high levels during IBDs, therefore playing a functional role in their pathogenesis [4]. Moreover, in IL- $10^{-1-}$ mice, IL-6 can also be considered an inflammatory mediator responsible for maintaining/increasing the intestinal inflammation [5] and its levels were therefore measured. On the other hand, IFN- $\gamma$, identified as a major mediator initiating colitis in IL-10 $10^{-1-}$ neonates $[5,27]$, showed increased levels in IL$10^{-/-}$mice as a result of failed regulatory $\mathrm{T}$ cells production or even functionality in the absence of IL-10, suggesting that Th1 cells are activated very early in the disease process [27]. A higher IFN- $\gamma$ production is related to a more severe colitis [28].

To confirm that the genetically modified L. lactis strain is indeed transient through the gastrointestinal tract and does not colonize it, bacterial translocation to the spleen and liver was evaluated. No bacterial translocation was observed in these organs at any of the evaluated times $(2 \mathrm{~h}, 4 \mathrm{~h}, 6 \mathrm{~h}, 12 \mathrm{~h}$ and $24 \mathrm{~h})$ after oral administration. This is a particularly important safety parameter regarding human use.

The work here presented represents the last step in validating this DNA delivery strategy using the L. lactis MG1363 bacterial strain. When first constructing the pValac:il-10 plasmid, this was tested for its transfection efficiency and subsequent IL-10 production and secretion by eukaryotic cells through ELISA, confocal microscopy and FACS [18]. Following, this L. lactis MG1363 FnBPA+ (pValac:il-10) strain was tested in two animal models to evaluate not only the success of the strategy in delivering the pValacil-10 plasmid and following in situ IL-10 production and secretion by the animals cells, but also its immunomodulatory potential in diminishing the onset and development of intestinal inflammation due to increased IL-10 production, when compared with the control groups. In 2013, del Carmen and co-workers demonstrated that the severity of TNBS-induced intestinal inflammation decreased in mice after administration of this strain as a result of an increase in IL-10 levels and decrease in IFN- $\gamma$ and IL-17 levels, when compared to the not treated groups [18]. Later, Zurita-Turk et al. demonstrated that administration of this L. lactis strain resulted in decreased severity of DSS-induced intestinal inflammation, probably also due to increased IL-10 levels and decreased IL-6 levels [19]. These studies showed that direct IL-10 production at inflammation sites produced an antiinflammatory environment, as well as downregulated Th1-and Th17-mediated inflammation, capable of diminishing the onset and severity of the disease.

Thus, the main interest when testing this bacterial strain in the IL- $10^{-/-}$model was to evaluate if animals would produce IL-10 and consequently diminish the development of the intestinal inflammation and as such, validate the efficiency of this DNA delivery strategy. The results here presented are very exciting, as they demonstrate that our strategy leads to IL-10 production by mice that are naturally not able to, as well as higher production when compared to healthy mice capable of normally producing this cytokine, however, at a lower rate.

However, this current study presents one research limitation: FACS analyses were not performed. FACS analyses would have brought better knowledge regarding the mechanism of pValac:il-10 delivery and uptake/invasion into eukaryotic cells, as well as which are the IL-10producing cell populations. From the obtained results it can be stated that the proposed strategy was successful, as the pValac:il-10 plasmid was delivered to eukaryotic cells in IL-10 ${ }^{-/-}$mice and subsequent IL-10 production was responsible diminish the development of intestinal inflammation. Nevertheless, the exact mechanism and which cells populations were involved, were not elucidated. In this context, future studies are required to answer these current research limitations.

\section{Conclusions}

To evaluate the therapeutic capacity in preventing the onset of spontaneous enterocolitis in $\mathrm{IL}-10^{-1-}$ mice, $L$. lactis MG1363 FnBPA+ (pValac:il-10) was administered to 2-week old $\mathrm{IL}-10^{-/-}$mice for six consecutive weeks. One feature characterizing the development of this disease is low weight gain, and mice receiving our therapy showed normal weight gain along the 6 weeks of treatment, comparable to the healthy control group. Moreover, these animals also showed overall lower macroscopic and histological damages, both in the AC and DC, when compared to not treated IL-10 $10^{-1-}$ mice, showing capability in attenuating the pathology's development and improving histological patterns. Moreover, tendency to lower IL-6 and IFN- $\gamma$ levels were observed in the AC and small intestine, probably due to IL-10 production. 
All these results show that administration of the L. lactis MG1363 FnBPA+ strain carrying the therapeutic pValac:il-10 plasmid attenuated the development of spontaneous intestinal inflammation in IL- $10^{-/-}$mice by maintaining an anti-inflammatory environment in the GIT. Thus, administration of this strain led to IL-10 production by these animals and in this way diminished the onset of inflammation. These results, together with those presented in the TNBS- and DSS-induced inflammatory models, strengthen the potential of this strategy in the therapeutic treatment of IBD.

\section{Methods}

\section{Bacterial strains, growth conditions and plasmid}

The bacterial strains and plasmid used in this work are listed in Table 2. L. lactis strains were grown in M17 medium (Difco, Sparks, MD, USA) supplemented with $0.5 \%$ glucose (GM17) at $30^{\circ} \mathrm{C}$ without shaking and bacterial selection was performed by addition of $10 \mu \mathrm{g} / \mathrm{mL}$ of chloramphenicol $(\mathrm{Cm})$ and/or $5 \mu \mathrm{g} / \mathrm{mL}$ of erythromycin (Ery). L. lactis cultures were grown until an $\mathrm{OD}_{600}$ of 1.0-1.2 and stocked in glycerol $80 \%$ (1:4); on animal feedings day, doses were centrifuged to eliminate any traces of antibiotic and medium and resuspended in $1 \mathrm{~mL}$ of saline solution $(0.15 \mathrm{M} \mathrm{NaCl})$.

\section{Animals}

To evaluate the therapeutic capacity of the L. lactis MG1363 FnBPA+ (pValac:il-10) strain in diminishing and/or preventing the onset of enterocolitis, wild-type and $\mathrm{IL}-10^{-1-}$ mice on a $129 \mathrm{~Sv} / \mathrm{Ev}$ genetic background were used, as these are the most susceptible to colitis development with homogeneous clinical manifestation [5]. As these animals develop a spontaneous and gradual intestinal inflammation when not maintained in SPF conditions, mice were, for experimental procedures, maintained in collective cages in conventional conditions in an environmentally controlled room with a 12-h light/dark cycle and free access to water and food.

For experimental procedures, experimental groups were adjusted in relation to the animal's weight at the age of 2 weeks and consisted of: i) healthy control group, ii) $\mathrm{IL}-10^{-/-}$control group (KO group) and the IL-10 $0^{-/-}$ groups that received the iii) L. lactis MG1363 FnBPA+ strain (FnBPA group) or the iv) L. lactis MG1363
FnBPA+ (pValac:il-10) strain (pValac:il-10 group). As the disease is already apparent at the age of 4 weeks, the in vivo assays started with 2-week old mice that received intragastrically, over six consecutive weeks, $100 \mu \mathrm{L}$ of the corresponding bacterial strain as suspension at a dose of $2 \times 10^{9} \mathrm{CFU} / 100 \mu \mathrm{L}$ or $100 \mu \mathrm{L}$ of $0.9 \%$ saline solution (control groups) per day. After 6 weeks (at the age of 8 weeks), all mice were euthanized by overdose of a ketamine $(100 \mathrm{mg} / \mathrm{kg}) / x y l a z i n e(10 \mathrm{mg} / \mathrm{kg})$ mixture. The total $\mathrm{n}$ of this experimental procedure was 9 .

Mice were kindly donated by Dr. Ana Maria Caetano de Faria from the Federal University of Minas Gerais (UFMG - Belo Horizonte, Brazil). All animal procedures and manipulations were approved by the Ethics and Research Committee on Animal Experiments (CEUA) of the Biological Institute of the Universidade Federal de Minas Gerais (UFMG - Belo Horizonte, Brazil) with protocol number 66/2011.

\section{Macroscopic and histologic assessment of enterocolitis}

Animals' weight was rigorously evaluated during the 6 weeks of experimental procedure to assess the macroscopic damage of the disease. After this time, as already described in the previous section, animals were euthanized by overdose of a ketamine/xylazine mixture and the colons were excised to assess colonic inflammation using a previously defined scoring system that evaluates the following features: presence or absence of adhesions, strictures and diarrhea (loose, watery stool), and bowel wall thickness $(\mathrm{mm})$. As enterocolitis can affect the colon in different degrees, all colon samples were divided in ascendant and descendant regions for separate evaluation.

All colon samples were fixed in formalin and processed for histologic analysis. HE stained sections were blindly scored based on a semiquantitative scoring system previously described [30] that grades the following features: destruction extent of normal mucosal architecture (0: normal; 1: mild, 2: moderate and 3: extensive damage), presence and degree of cellular infiltration ( 0 : normal; 1: mild, 2: moderate and 3: transmural infiltration), extent of muscle thickening (0: normal; 1 : mild, 2: moderate and 3: extensive thickening), presence (1) or absence (0) of crypt abscesses and presence (1) or absence (0) of goblet cell depletion. Scores for each

Table 2 Bacterial strains and plasmid

Bacterial strain
Lactococcus lactis MG1363 FnBPA+
Lactococcus lactis MG1363 FnBPA+ (pValac:il-10)

Plasmid

pValac:il-10

\author{
Characteristics \\ L. lactis MG1363 strain expressing FnBPA of S. aureus \\ L. lactis MG1363 strain expressing FnBPA of S. aureus \\ carrying the pValac:il-10 plasmid
}

Characteristics

(pCMV/CmR/RepA/RepC/IL-10)
Font

[29]

[18] 
feature were summed up to a maximum possible score of 11 .

\section{Tissue preparation and cytokine assay}

Samples of AC and DC, small intestine and spleen were weighed and homogenized in phosphate-buffered saline (PBS) containing $0.05 \%(\mathrm{v} / \mathrm{v})$ Tween-20, $0.1 \mathrm{mM}$ phenylmethylsulphonyl fluoride, $0.1 \mathrm{mM}$ benzethonium chloride, $10 \mathrm{mM}$ EDTA and $20 \mathrm{KIU}$ Aprotinin A using a tissue homogenizer $(1 \mathrm{~mL} / 0.1 \mathrm{~g})$ for cytokine assays. Tissue fragments were then homogenized and centrifuged for $10 \mathrm{~min}$ at $600 \mathrm{~g}$ and $4{ }^{\circ} \mathrm{C}$ and supernatants were collected for cytokine assay, as previously described [31]. Briefly, 96-well plates (Nunc) were coated with purified monoclonal antibodies reactive with cytokines IL-6, IL10 and IFN- $\gamma$ (BD-Pharmingen) overnight at $4{ }^{\circ} \mathrm{C}$. Wells were washed the next day, supernatants were added and plates incubated overnight at $4{ }^{\circ} \mathrm{C}$. Following, biotinylated monoclonal antibodies against cytokines were added and plates were incubated for $2 \mathrm{~h}$ at room temperature. Color reactions were developed at room temperature with $100 \mu \mathrm{L} /$ well of orthophenylenediamine (OPD) (1 mg/mL) (Sigma, St. Louis, MO, USA), 0.04\% $\mathrm{H}_{2} \mathrm{O}_{2}$ substrate in sodium citrate buffer. Reactions were interrupted by addition of $20 \mu \mathrm{L} /$ well of $2 \mathrm{~N} \mathrm{H}_{2} \mathrm{SO}_{4}$ and absorbance was measured at $492 \mathrm{~nm}$ by an ELISA microplate reader (Bio-Rad). Results were expressed as concentration $(\mathrm{pg} / \mathrm{mL})$, according to the standard curve.

\section{Bacterial translocation}

IL- $10^{-/-}$mice received $100 \mu \mathrm{L}$ of L. lactis MG1363 FnBPA+ (pValac:il-10) intragastrically at a dose of $2 \times$ $10^{9} \mathrm{CFU} / 100 \mu \mathrm{L}$. Spleen and liver were collected under strict aseptic conditions $2 \mathrm{~h}, 4 \mathrm{~h}, 6 \mathrm{~h}, 12 \mathrm{~h}$ and $24 \mathrm{~h}$ after bacterial administration. Tissues were macerated in $500 \mu \mathrm{L}$ of $0.9 \%$ saline and $100 \mu \mathrm{L}$ of this homogenate was plated in M17 medium (Sigma-Aldrich) supplemented with agar, $0.5 \%$ glucose, chloramphenicol $(10 \mu \mathrm{g} / \mathrm{mL})$ (Sigma-Aldrich) and erythromycin $(5 \mu \mathrm{g} / \mathrm{mL})$ (Sigma-Aldrich). Plates were incubated at $30^{\circ} \mathrm{C}$ for $24 \mathrm{~h}$.

\section{Statistical analysis}

Statistical analyses were performed using the GraphPad Prism 5.0 software (San Diego, CA, USA). Student's ttest or analysis of variance (ANOVA) followed by a Tukey comparison post-hoc test were used to assess the significance of differences among groups. Means were considered statistically different when $p<0.05$ and all results were expressed as mean \pm standard deviation (SD).

\section{Abbreviations}

AC: Ascending colon; ANOVA: Analysis of variance; CD: Crohn's disease; Cm: Chloramphenicol; DC: Descending colon; DSS: Dextran Sodium Sulphate; Ery: Erythromycin; GIT: Gastrointestinal tract; HE: Hematoxylin-eosin; IBD: Inflammatory bowel diseases; IL-10: Interleukin-10; IL-10 ${ }^{-1-}$ : IL-10- deficient mouse model; L. lactis: Lactococcus lactis; OPD: Orthophenylenediamine; PBS: Phosphate-buffered saline; SD: Standard deviation; SPF: Specific-pathogen-free; TNBS: 2,4,6-Trinitrobenzenesulfonic acid; UC: Ulcerative colitis; UFMG: Universidade Federal de Minas Gerais

\section{Acknowledgements}

We acknowledge financial support from the Coordenação de Aperfeiçoamento de Pessoal de Nível Superior (CAPES), Conselho Nacional de Desenvolvimento Científico e Tecnológico (CNPq), and Fundação de Amparo à Pesquisa do Estado de Minas Gerais (FAPEMIG).

\section{Authors' contributions}

MZT conceived the study, performed the research, collected, analyzed and interpreted the data and wrote the paper. BMS, CPC, VBP, VPC and TMP participated with the realization of the experiments and contributed to the scientific discussion. AMCF kindly provided the mice for animal experimentation and contributed to the scientific discussion. DCCM carried out all histological analyses and contributed to the scientific discussion. AM conceived the study, participated in its design and coordination, helped to draft the manuscript and gave final approval for publication. All authors read and approved the final manuscript. MZT and AM share co-senior authorship.

\section{Funding}

This work received financial support from the Conselho Nacional de Desenvolvimento Científico e Tecnológico (CNPq) to purchase all material required to perform the research and from the Coordenação de Aperfeiçoamento de Pessoal de Nível Superior (CAPES) responsible for the grants of students involved in this project.

\section{Availability of data and materials}

The datasets used and/or analyzed during the current study are available from the corresponding author on reasonable request.

\section{Ethics approval and consent to participate}

All animal procedures and manipulations were approved by the Ethics and Research Committee on Animal Experiments (CEUA) of the Biological Institute of the Universidade Federal de Minas Gerais (UFMG - Belo Horizonte, Brazil) with protocol number 66/2011.

Consent for publication

Not applicable.

\section{Competing interests}

The authors declare that they have no competing interests.

\section{Author details}

'Laboratório de Tecnologia Genética, Departamento de Biologia Geral, Instituto de Ciências Biológicas, Universidade Federal de Minas Gerai, Av. Antônio Carlos, 6627, Pampulha, 31, Belo Horizonte, MG 270-901, Brazil. ${ }^{2}$ Laboratório de Imunobiologia, Departamento de Bioquímica e Imunologia, Instituto de Ciências Biológicas, Universidade Federal de Minas Gerai, Belo Horizonte, Minas Gerais, Brazil. 'Laboratório de Alergia e Inflamação, Departamento de Morfologia, Instituto de Ciências Biológicas, Universidade Federal de Minas Gerai, Belo Horizonte, Minas Gerais, Brazil.

Received: 23 May 2019 Accepted: 16 July 2020

Published online: 23 July 2020

\section{References}

1. Sventoraityte J, Zvirbliene A, Kiudelis G, Zalinkevicius R, Zvirbliene A, Praskevicius A, Kupcinskas L, Tamosiunas V. Immune system alterations in patients with inflammatory bowel disease during remission. Medicina (Kaunas). 2008:44:27-33.

2. Fiocchi C. Inflammatory bowel disease: etiology and pathogenesis. Gastroenterol. 1998;115:182-205.

3. Lakatos $L$, Lakatos PL. Changes in the epidemiology of inflammatory bowel diseases. Orv Hetil. 2007;148(5):223-8.

4. Kühn R, Lohler J, Rennick DM, Rajewsky K, Müller W. Interleukin-10-deficient mice develop chronic enterocolitis. Cell. 1993;75(2):263-74.

5. Berg DJ, Davidson N, Kühn R, Müller W, Menon S, Holland G, ThompsonSnipes L, Leach MW, Rennick DM. Enterocolitis and colon cancer in 
interleukin-10-deficient mice are associated with aberrant cytokine production and CD4+ Th1-like responses. J Clin Invest. 1996;98(4):1010-20.

6. Asadullah K, Sterry W, Volk HD. Interleukin-10 therapy - review of a new approach. Pharmacol Rev. 2003;55(2):241-69.

7. Skeen MJ, Miller MA, Shinnick TM, Ziegler HK. Regulation of murine macrophage IL-12 production: activation of macrophages in vivo, restimulation in vitro, and modulation by other cytokines. J Immunol. 1996; 156(3):1196-206.

8. Moore KW, de Waal MR, Coffman RL, O'Garra A. Interleukin-10 and the interleukin-10 receptor. Annu Rev Immunol. 2001;19:683-765.

9. Mocellin S, Marincola F, Rossi CR, Nitti D, Lise M. The multifaceted relationship between IL-10 and adaptive immunity: putting together the pieces of a puzzle. Cytokine Growth Factor Rev. 2004;15(1):61-76.

10. de Moreno de LeBlanc A, del Carmen S, Zurita-Turk M, Santos Rocha C, van de Guchte M, Azevedo V, Miyoshi A, LeBlanc JG. Importance of IL-10 modulation by probiotic microorganisms in gastrointestinal inflammatory diseases. ISRN Gastroenterol. 2011;1(1):1-10.

11. Colombel FF, Rutgeerts $P$, Malchow H, Jacyna M, Nielsen $O H$, Rask-Madsen J, Van Deventer S, Ferguson A, Desreumaux P, Forbes A, Geboes K, Melani L, Cohard M. Interleukin 10 (Tenovil) in the prevention of postoperative recurrence of Crohn's disease. Gut. 2001;49:42-6.

12. Schreiber $\mathrm{S}$, Fedorak RN, Nielsen $\mathrm{OH}$. Safety and efficacy of recombinant human interleukin 10 in chronic active Crohn's disease, Crohn's disease IL10 cooperative study group. Gastroenterol. 2000;119:1461-72.

13. Van Montfrans C, Van de Ende A, Fedorak RN, Gangl A, Elson CO, Rutgeerts P, Schreiber S, Wild G, Hanauer S, Grint P, Van Deventer SJH. Anti- and proinflammatory effects of interleukin 10 in mild to moderate Crohn's disease. Gastroenterol. 1999;11(12):A46.

14. Steidler L, Vandenbroucker K. Genetically modified Lactococcus lactis: novel tools for drug delivery. Int J Dairy Technol. 2006;59(2):140-6.

15. Li MC, He SH. IL-10 and its related cytokines for treatment of inflammatory bowel disease. World J Gastroenterol. 2004;10(5):620-5.

16. Braat $H$, Rottiers $P$, Hommes DW. A phase I trial with transgenic bacteria expressing interleukin-10 in Crohn's disease. Clin Gastroenterol Hepatol. 2006;4(6):754-9.

17. Pontes DS, de Azevedo MS, Chatel JM, Langella P, Azevedo V, Miyoshi A Lactococcus lactis as a live vector: heterologous protein production and DNA delivery systems. Protein Expr Purif. 2011;79(2):165-75.

18. del Carmen S, Zurita-Turk M, Lima A, Coelho dos Santos JS, Leclerca SY, Chatel JM, Azevedo V, de Moreno de LeBlanc A, Miyoshi A, JG LB. A novel interleukin-10 DNA mucosal delivery system attenuates intestinal inflammation in a mouse model. Eur J Inflamm. 2013;11(3):641-54.

19. Zurita-Turk M, del Carmen S, Santos ACG, Pereira VB, Cara DC, Leclercq SY, de Moreno de LeBlanc A, Azevedo V, Chatel JM, LeBlanc JG, Miyoshi A. Lactococcus lactis carrying the pValac DNA expression vector coding for IL10 reduces inflammation in a murine model of experimental colitis. BMC Biotechnol. 2014;14:73.

20. Bhavsar MD, Amiji MM. Oral IL-10 gene delivery in a microsphere-based formulation for local transfection and therapeutic efficacy in inflammatory bowel disease. Gene Ther. 2008;15:1200-9.

21. Yao J, Wang J-Y, Lai M-G, Li Y-X, Zhu H-M, Shi R-Y, Mo J, Xun A-Y, Jia C-H, Feng J-L, Wang L-S, Zeng W-S, Liu L. Treatment of mice with dextran sulfate sodium-induced colitis with human interleukin 10 secreted by transformed bifidobacterium longum. Mol Pharm. 2011;8:488-97.

22. Schotte L, Steidler L, Vandekerckhove J, Remaut E. Secretion of biologically active murine interleukin-10 by Lactococcus lactis. Enzyme Microb Techno1. 2000;27:761-5.

23. Steidler L, Hans W, Schotte L, Neirynck S, Obermeier F, Falk W, Fiers W, Remaut $\mathrm{E}$. Treatment of murine colitis by Lactococcus lactis secreting interleukin-I0. Science. 2000;289:1352-5.

24. Innocentin S, Guimarães V, Miyoshi A, Azevedo V, Langella P, Chatel JM, Lefevre F. Lactococcus lactis expressing either Staphylococcus aureus fibronectin-binding protein a or listeria monocytogenes internalin a can efficiently internalize and deliver DNA in human epithelial cells. Appl Environ Microbiol. 2009;75:4870-8.

25. Mosmann TR, Coffman RL. TH1 and TH2 cells: different patterns of lymphokine secretion lead to different functional properties. Ann Rev Immunol. 1989;7:145-73.

26. Madsen $\mathrm{KL}$, Jijon $\mathrm{H}$. IL-10 and IL-2 Knockout Mice - Effect on Intestinal Inflammation. Cytokine Knockouts, Part of the Contemporary Immunology book series (CONTIM); 2003. p. 237-51.
27. Davidson NJ, Fort MM, Müller W, Leach MW, Rennick DM. Insufficient counter regulation of a Th1 response. Int Rev Immunol. 2000;19:91-121.

28. Mikami Y, Kanai T, Sujino T, Ono Y, Hayashi A, Okazawa A, Kamada N, Matsuoka K, Hisamatsu T, Okamoto S, Takaishi H, Inoue N, Ogata H, Hibi T. Competition between colitogenic Th1 and Th17 cells contributes to the amelioration of colitis. Eur J Immunol. 2000;40(9):2409-22.

29. Que YA, Francois P, Haefliger JA, Entenza JM, Vaudaux P, Moreillon P. Reassessing the role of Staphylococcus aureus clumping factor and fibronectin-binding protein by expression in Lactococcus lactis. Infect Immunol. 2001;69:6296-302.

30. McCafferty DM, Sihota E, Muscara M, Wallace JL, Sharkey KA, Kubes P. Spontaneously developing chronic colitis in IL-10/iNOS double-deficient mice. Am J Phys. 2000;279(1):G90-9.

31. Maron R, Hancock WW, Slavin A, Hattori M, Kuchroo V, Weiner HL. Genetic susceptibility or resistance to autoimmune encephalomyelitis in $\mathrm{MHC}$ congenic mice is associated with differential production of pro- and antiinflammatory cytokines. Int Immunol. 1999;11(9):1573-80.

\section{Publisher's Note}

Springer Nature remains neutral with regard to jurisdictional claims in published maps and institutional affiliations.

Ready to submit your research? Choose BMC and benefit from:

- fast, convenient online submission

- thorough peer review by experienced researchers in your field

- rapid publication on acceptance

- support for research data, including large and complex data types

- gold Open Access which fosters wider collaboration and increased citations

- maximum visibility for your research: over $100 \mathrm{M}$ website views per year

At BMC, research is always in progress.

Learn more biomedcentral.com/submissions 